Journal of Linguistics

http://journals.cambridge.org/LIN

Additional services for Journal of Linguistics:

Email alerts: Click here

Subscriptions: Click here

Commercial reprints: Click here

Terms of use : Click here

\title{
Negation, 'presupposition' and metarepresentation: a response to Noel Burton-Roberts
}

ROBYN CARSTON

Journal of Linguistics / Volume 35 / Issue 02 / July 1999, pp 365 - 389

DOI: null, Published online: 08 September 2000

Link to this article: http://journals.cambridge.org/abstract_S0022226799007653

How to cite this article:

ROBYN CARSTON (1999). Negation, 'presupposition' and metarepresentation: a response to Noel Burton-Roberts. Journal of Linguistics, 35, pp 365-389

Request Permissions : $\underline{\text { Click here }}$ 
J. Linguistics 35 (1999), 365-389. Printed in the United Kingdom

(C) 1999 Cambridge University Press

\title{
Negation, 'presupposition' and metarepresentation: a response to Noel Burton-Roberts ${ }^{1}$
}

\author{
ROBYN CARSTON \\ Department of Phonetics and Linguistics, University College London
}

(Received 9 November I998)

\section{INTRODUCTION}

Metalinguistic negation (MN) is interesting for at least the following two reasons: (a) it is one instance of the much broader, very widespread and various phenomenon of metarepresentational use in linguistic communication, whose semantic and pragmatic properties are currently being extensively explored by both linguists and philosophers of language; (b) it plays a central role in recent accounts of presupposition-denial cases, such as 'The king of France is not bald; there is no king of France'. It is this latter employment that discussion of metalinguistic negation has focused on since Horn (1985)'s key article on the subject. While Burton-Roberts (I989a, I989b) saw the MN account of presupposition-denials as providing strong support for his semantic theory of presupposition, I have offered a multilayered pragmatic account of these cases, which also involves $\mathrm{MN}$, but maintains the view that the phenomenon of presupposition is pragmatic (Carston 1994, 1996, 1998a).

In this response to Burton-Roberts's reply (I999, in this volume) to Carston (I998a), I would like, eventually, to shift the focus to the first of the two issues, $\mathrm{MN}$ as a subtype of metarepresentational use. But since several of Burton-Roberts's (B-R hereafter) comments concern presuppositional issues and, more pressingly, the matter of the semantics/pragmatics distinction, I will address these first, albeit fleetingly. So in the next section, I return briefly to Horn's (alleged) dilemma and the (alleged) incompatibility of a pragmatic approach to presupposition with a treatment of presupposition-denials in terms of MN. In Carston (I998a), I presented a range of evidence against B-R's contention that presupposition-denials, like Horn's cases involving corrections of linguistic form (for example, 'I didn't see two

[I] Many thanks to Deirdre Wilson and Eun-Ju Noh for stimulating conversations on metarepresentational use, and to Vladimir Žegarac for helpful comments on an earlier draft. I'm very grateful, once again, to Noel Burton-Roberts, for an enjoyable e-mail exchange on pineapples, sacking vs. killing and other issues relevant to this paper. 
mongeese; I saw two mongooses'), are semantic contradictions. B-R's (I989b) 'semantic contradiction' account has now been developed into (or replaced by) his account (I993/97) in terms of a 'PRAGMATIC contradiction', which, as he points out, bears striking similarity to my own. The remaining differences between us concern the encoded semantic content of negative presuppositional sentences and the principle responsible for bridging the gap between the encoded semantics and the presupposition-preserving (henceforth P-preserving) interpretation, which is then contradicted by the followup clause. These differences are the subject of section 3. Then, in the following section, I touch again on the ever contentious semantics/ pragmatics distinction. There are several ways of drawing this distinction, due to there being several different ways of construing semantics. This is only problematic if one is unclear what sort of semantics one is dealing in; I claim that the relevance-theoretic distinction, which I employ, is both clear and coherent.

In the final section of his paper, B-R reconsiders the nature of 'metalinguistic negation', distinguishes a special subclass (his '! $\mathrm{MN}$ ') and makes some pertinent observations about slip of the tongue cases ('flaunting' for 'flouting', for instance); this is very interesting and marks a moving on from the issues that he and I, probably for quite long enough, have been debating. Following his positive lead, in my final section, I look at a range of different types of metarepresentation falling within the scope of negation. At this stage, the main point of difference between us concerns the interpretation of the negation operator itself: B-R claims that in his ! MN cases it is non-truth-functional, while I reiterate my position that it is the standard truth-functional negation, operating over a propositional form, a substantial part of which is not semantically encoded but must be recovered by pragmatic enrichment. The presence of formal linguistic (phonetic, morphological, syntactic) material, or even of non-linguistic sounds or marks, in the scope of the negation operator makes no difference to the interpretation of the operator itself.

\section{Presupposition and ambiguity of Negation}

B-R thinks Horn's views on negation and presupposition-cancellation presented him with a dilemma; I don't (and nor does Horn). Horn (I985, I989) advocated a presupposition-cancelling semantics for negation (his predicate-denial negation), while insisting that, in actual use, presuppositioncancellation arises most naturally as metalinguistic negation (MN). That there is no inconsistency in this position is now conceded by B-R (I999), so this is no longer a live issue and need not detain us long. However, he reasserts his view that Horn's MN account of presupposition-denial cases was most naturally and economically complemented by a semantically-based account of presupposition, and that all that held Horn (1985) back from 
taking up this position was his mistaken view that a semantic approach to presupposition entails the semantic ambiguity of the negation operator (a Ppreserving operator and a P-cancelling operator).

However, Horn's position was motivated not just by his acceptance of this ambiguity view (standard among both the semantic and pragmatic presupposition camps at the time), a view that B-R has indeed effectively rebutted, but also by his conviction that presupposition is simply not a semantic relation (no matter what this entails about the semantics of negation): "The abandonment of semantic presupposition [] was not occasioned by perversity or whimsy, or solely by the specter of the ambiguity of negation. The balance of the evidence leads me to agree with the prevailing view (expressed most forcefully in Lycan I984: chapter 4) that the conceptual obscurities and implementational difficulties besetting the notion of logical presupposition render it at best otiose for the description of natural language semantics' (Horn 1989: 487). Again, in his review of B-R (I989b), Horn (I990) restates his commitment to a pragmatic (Gricean) treatment of the phenomenon of presupposition, and points out an important concession made by $\mathrm{B}-\mathrm{R}$ in the direction of the anti-presuppositionalists: the vacuousness of a singular term does not always lead to a truth-value gap but may be 'irrelevant' to the falsity of the sentence in question. An example of this is (Ia), which is intuitively plainly false, and is accepted as such by B-R (I989b: ch. 9):

(I) (a) The king of France is standing next to me.

(b) The king of France is bald.

(c) The king of France is standing next to an aardvark.

In Horn's view all three of these are false, in accordance with the antipresuppositional view, since all three have the false entailment, that there is a king of France. The difference between them, leading to an intuition of truth-valuelessness in the case of ( $\mathrm{Ib}$ ), is in their verifiability/falsifiability; it's an easy matter to determine that the king of France is not standing next to me, while ( $\mathrm{I} b$ ) can only be falsified indirectly by determining that France has no king, and (Ic) seems to be an intermediate case. Relative ease or difficulty in determining the truth/falsity of a sentence/utterance does not bear on its actual truth-value; it is not a semantic matter. Horn concludes his review: 'B-R's revised theory of semantic presupposition has the effect of "loosening the tie between presupposition failure and lack of truth value" (I85). Loosen that tie a bit more, and the doctrine of semantic presupposition falls of its own weight. I have argued that that last step must in fact be taken, with presupposition characterized as a pragmatic non-truth-conditional relation supplementing an entailment-based approach to the king of France's baldness incorporated within a bivalent Aristotelian semantics.' (Horn I990: $50 \mathrm{I})$. 
It follows from the standard presuppositional view (the Frege-Strawson account with its P-preserving negation operator) that presupposition-denials are semantic contradictions. B-R (I999) argues that this should have made the pull towards the semantic presuppositional line all the stronger for Horn since the presupposition-denial cases appear to form a natural class with Horn's other examples of MN. But this is really not a good line of argument. It is only semantic presuppositionalists (including B-R (I989b), whose account of P-preservation, though different from Frege-Strawson's, was still wholly semantic) who take P-denials to be intrinsically contradictory. Horn did not, and, as B-R recognizes, the evidence I have presented (at least some of it adapted from Horn (1990), by the way) shows that he, rather than the semantic presuppositionalists, is right on this point: presupposition-denials are NOT linguistic semantic contradictions. Furthermore, Horn has never required, and clearly doesn't believe, that every case of $\mathrm{MN}$ is a semantic contradiction; many of his other examples of $\mathrm{MN}$ are patently not cases of descriptive contradiction at any level (see the sample given in Carston (I998a: section 3.3)).

Horn did not face a dilemma. His position, which I endorse, was, and is, that there are no semantic presuppositions, that sentence negation cancels all entailments (including those that are intuitively presuppositional), that presupposition-denials are not semantic contradictions, and that presupposition-cancellation is most naturally manifest in an interpretation which involves the metarepresentation of the positive presuppositional utterance in the scope of negation. Where fault could be found with Horn is in his omission of anything much by way of an account of the interpretive processes which map the encoded semantics of the negative sentence (presupposition-cancelling) onto the pragmatically derived metarepresentational understanding (also presupposition-cancelling). I believe that my relevance-theoretic account (Carston 1994, 1996, I998a) remedies this omission.

\section{TWO ACCOUNTS OF THE INTERPRETATION OF PRESUPPOSITION- DENIALS}

Let's move now to a comparison of B-R's and my accounts of the main sort of case at issue here: the utterance of a negative presuppositional sentence, followed by an explicit denial of the presupposition, focusing on those instances where the first interpretation accessed is descriptive, a contradiction is derived, and a reinterpretation process results in an element of metarepresentation in the scope of negation. For ease of exposition, I'll stick to the standard existential case, represented schematically here:

(2) The $F$ is not $G$; there is no $F$.

According to B-R (I999: 355-356), his I993/97 account and mine in the 
paper he is responding to are very similar; they both look as follows (omitting the second clause which remains the same throughout):

(3) (i) encoded semantics: not [the $F$ is $G]$

(ii) first interpretation: [the $F$ is not-G]

(iii) second interpretation: not ['the $F$ is $G$ ']

This is correct as far as it goes, but it obscures a number of differences, of which the main ones are (a) the interaction of the negation operator and the existential presupposition in (i); (b) the principle responsible for the first interpretation, on which the presupposition is preserved; (c) the principle responsible for the rejection of (ii) and the reanalysis leading to (iii). In the following subsections, I look at each of these in turn.

\section{I The semantic encodings}

On my account, there is no semantic relation of presupposition distinct from ordinary entailment, and the negation operator is maximally wide in scope, so it cancels all entailments of the corresponding positive; this is how the representation in (3i) above is standardly construed. From that point on, it is up to pragmatics to determine the relevant scope of the negation operator.

B-R's semantics is a more complicated matter. It too consists of a wide scope negation which cancels all the entailments of its corresponding positive. But among these cancelled entailments are presuppositions (weakbut-not-strong entailments), specifically the existential presupposition, and these are neither logically denied not logically affirmed. They are not logically denied because it is in the semantic nature of presuppositions that their falsity alone cannot falsify a positive sentence that entails them, and they are not logically affirmed because they are in the scope of negation and so are cancelled. Recall that B-R's ultimate aim here is to capture the intuition that presuppositions are preserved under negation, but without assuming a presupposition-preserving negation operator, against which he has presented convincing arguments. So he shifts the terminology from 'cancellation/ preservation' to the seemingly more pragmatic notions of 'denial/ affirmation' and says 'the SPEAKER WHO ASSERTS not-A neither logically affirms nor logically denies the presuppositions of A' (my emphasis).

Because I find this obscure, I make just two comments and move on: (a) as regards the SEMANTICS of the sentence, surely all the entailments (both the strong and the presuppositional) are cancelled, while none is denied (denial being an act of a language user); (b) the determination that what a speaker is denying is one or more of the strong entailments requires a process of reasoning about the possible grounds for a speaker's utterance of the negative sentence; this seems to be a pragmatic process. 


\subsection{The presupposition-preserving interpretation}

For current purposes, we are assuming that the interpretation of the negative sentence which is accessed first is the P-preserving interpretation. On my account, this is but one of myriad cases of relevance-driven pragmatic enrichment at the level of the proposition expressed. On B-R's account, it is due to a quite general cognitive tendency towards bivalence (CTB), which kicks in automatically because of the situation created by his encoded semantics: the existential implication falls within the domain of denial (the scope of the negation operator) but is not denied; hence it is tacitly affirmed (preserved). Before looking more closely at the operation of the cognitive tendency (called the Cognitive Bivalence Principle in B-R (I993/97)), I'll address some of the points B-R (I999) makes about my account and about pragmatic treatments more generally.

\subsection{Pragmatic accounts}

In Carston (I998a), I began by making a broad distinction between semantic presuppositionalists, who do not account for P-preservation pragmatically, and anti-presuppositionalists (Atlas, Boer \& Lycan, Horn, Kempson, Wilson), who support a wide scope semantics for negation with a pragmatic derivation of the P-preserving understanding; most of these analyses were developed in the seventies and so the pragmatics was Gricean. I gave the relevance-theoretic account in the last section of that paper, so at earlier points characterized it as 'broadly Gricean', since it plainly aligns with the anti-presuppositionalists rather than the semantic presuppositionalists; so much the worse for me, in B-R's view, since Gricean accounts of Ppreservation are no good.

Before I point out the respects in which a relevance-theoretic pragmatic account differs from a Gricean pragmatic account, I feel compelled to make two demurring points regarding B-R's outline of a Gricean approach, neither of which I will pursue in detail. First, Grice's own account of the Ppreserving understanding of negative sentences is given in terms of a manner maxim of 'conversational tailoring' (see Grice I98I). I summarize drastically: assuming a Russellian semantics for descriptions and a wide scope negation, the pragmatics of P-preservation involves a comparison between different ways of expressing the same set of truth conditions (the negation of a set of three conjuncts: there is an $\mathrm{F}$, there is at most one $\mathrm{F}$, whatever is $F$ is $G$ ); the speaker's choice of the abbreviatory linguistic form 'The $F$ is not G', rather than a longer form involving conjunction or disjunction, invites the hearer to infer that the speaker implicates the existence of a unique F. The idea is that the speaker has tailored her utterance in such a way as to indicate which of the three truth conditions of the positive sentence is the focus of her negation. So Grice's account is quite different from the 'Gricean' account given by B-R and is not subject to the criticism he levels. 
Second, and more important, B-R's 'Gricean' account is not actually Gricean at all, if by Gricean we mean an account that employs Grice's system of maxims. Grice did not postulate a conversational maxim or pragmatic principle of the sort B-R calls on in his critique: 'Speakers are expected to give as much information as is compatible with their beliefs' (B-R I 999: 357). It doesn't take much thought to convince oneself that there is no such conversational principle governing our exchanges; speakers do not spill forth the contents of their minds willy nilly, and hearers do not expect, or wish, them to. See Green (1995) for an interesting expose of the problems with any such 'volubility' principle. Grice's first maxim of quantity is significantly different from this: it is a principle requiring 'SUFFICIENCY of information' and it is relativized to the 'current purposes of the conversation', it concerns a speaker's overall conversational CONTRIBUTION, not just what she SAYS, and it is further constrained by being but one in a system of interacting maxims, (the second quantity maxim, relevance and brevity all exercise a countervailing influence against excessive expressiveness).

I have to object to B-R's assertion that my account is not essentially different from the one he gives as Gricean. First, optimal relevance does not incorporate any notion of maximal informativeness or volubility. Second, a crucial ingredient in the relevance-theoretic account is COGNITIVE EFFORT, so, in that respect at least, it is closer to the manner maxim account of Grice (I98I), as outlined above. Consider the following examples (which are B-R's (I999) examples (I9)-(2 I)):

(4) (a) The king of France is not bald.

(b) There is no king of France.

(c) There is a king of France and he is not bald.

My argument was that the use of (4a) to communicate the proposition expressed by (4b) would not meet the criterion of optimal relevance since it would involve the hearer in decoding and manipulating the concept BALD, which has no role to play in the interpretation (does not lead to any cognitive effects). A speaker aiming at optimal relevance won't attempt this given the obvious availability of the more economical (hence more relevant) utterance, (4b).

When will a speaker choose to utter (4c) rather than (4a)? (4c) is longer and, arguably, more syntactically complex (involving a conjunction) than (4a), so on those grounds will require more processing effort from the hearer. On the other hand, in order to arrive at the same truth-conditional content the hearer of (4a) has to pragmatically narrow the scope of the negation operator. It follows from the precepts of Relevance theory that there is no reason to expect speakers to be as explicit as possible, that is, they should encode only what they cannot rely on their hearers to infer easily; semantic encoding merely provides clues to, or constraints on, interpretation. The idea is that the greater degree of spelling out that occurs in (4c) should arise only 
when the speaker has reason to doubt that the hearer will readily perform the pragmatic inference of negation narrowing on (4a), perhaps because the hearer has already expressed doubt about the existence of the king of France. ${ }^{2}$ Whatever the shortcomings of this account, it is not subject to the criticisms B-R levels at it (but then nor is Grice's).

\subsubsection{Cognitive bivalence}

Let's move now to B-R's own analysis. Recall that the input to this is an encoded semantic representation with a wide scope negation operator in whose scope there is material which is neither logically denied nor logically affirmed. An independent, quite general, cognitive (non-semantic) tendency or principle (the CTB) applies, so that, by default, that material is cognized as affirmed, because though it is in a domain of denial it has not been denied.

Intuitively, the idea that we have such a cognitive tendency to bivalence is appealing and B-R backs it up with some nice examples. For instance, if $\mathrm{X}$ is accused of cheating the expected response is a denial, so if $X$ remains silent she will standardly be taken to have tacitly affirmed that she cheated; if $Y$ says to X "You still love me, don't you?" and X is silent, she will be taken to have tacitly denied, in default of having overtly affirmed, that she still loves Y. In these cases the domain of denial or affirmation is established PRAGMATICALLY and is less absolute than the fixing of a domain by semantic means.

Interesting though this is, it raises a lot of questions. The only example we are given of a SEMANTICALLY established domain is a domain of denial which is the scope of a negation operator. Can a 'domain of affirmation' also be established semantically or not? If the negation operator establishes semantically a domain of denial, what sort of linguistic element could establish a domain of affirmation? One possibility is simply any unnegated sentence, the ' $S$ ' of B-R's 'Not-S'; others might be affirmatory phrases into which a sentence is embedded, for example, I affirm that $S$, It is true that $S$, $S$ indeed. Assuming there are semantically given domains of affirmation, the next question is: can there be any element of meaning which lies within such a domain but which is not affirmed, so, by the CTB, is tacitly denied? If not (and it does seem very unlikely), why not? Why should there be such an asymmetry concerning domains semantically established but not concerning

[2] I don't claim to have succeeded yet in giving a fully satisfactory account, though I think the direction is right; a complete story will have to confront the issue of the backgrounding and foregrounding of information that comes from different ways of linguistically packaging one and the same truth-conditional content (see relevant remarks in Sperber \& Wilson (I986: 2I3-2 I 5)). Furthermore, it may be that a procedural semantics for definites, as being developed by Breheny I999, which instructs a hearer to treat a discourse referent as given, strongly encourages the pragmatic narrowing of negation that excludes the existential implication from its scope. 
domains pragmatically established? These questions are raised but not addressed by B-R's exposition.

Second, fundamental to B-R's whole project is the assumption that we are speakers of a bivalent language but a bivalent language with gaps. So in the case where its presuppositional entailment is false, each of the following is truth-valueless:

(5) (a) The king of France is wise.

(b) Mary has stopped pestering John.

(c) Bill regrets taking Maggie to the disco.

That these sentences are neither true nor false (when their presupposition is false), is the basic intuition that any semantic presuppositionalist sets out to model. But isn't this an odd intuition for creatures in the grip of the cognitive tendency to bivalence to have? Shouldn't they be drawn toward finding these either true or false, if at all possible? And, since, by hypothesis, each sentence has a false entailment, shouldn't they simply find them false? Some people do, of course, but they are not semantic presuppositionalists. In brief, I find a tension in this theory between its respect for truth-value gaps and its employment of a Cognitive Bivalence Principle.

Finally, let's consider the truth-value of the representation in (3ii), the Ppreserving proposition expressed, in the case where, again, the presupposition concerning the existence of an $\mathrm{F}$ is false:

(3) (ii) [the $F$ is not-G]

Once more, the intuition to be captured is that here there is a truth-value gap. But there doesn't seem to be a gap on B-R's account; the result of the CTB is that the existential implication is affirmed, and since it is, by hypothesis, false, the proposition expressed must be false. B-R (I999: 354) says that this situation does not arise because the presupposition is 'only tacitly and NONTRUTH-CONDITIONALLY affirmed by default'; that is, its falsity does not affect the truth conditions of the sentence/utterance. If we take this claim on board, then the representation in (3ii) is misleading; the interpretation really consists of two distinct representations: the encoded semantic representation (in which the existential presupposition, though cancelled, is neither denied nor affirmed) and a representation affirming that there is an $\mathrm{F}$ (which would seem to be an implicature, since it is non-truth-conditional).

What, then, is the truth-conditional content of a P-preserving utterance of the form 'The F is not G'? The sentence itself seems to be truth-conditionally underspecified, awaiting some further process to establish the existential implication as affirmed or denied. On my view of natural language semantics, sentences are quite generally underspecified (so not truth-evaluable), and pragmatic enrichment is required before the truth-conditional content of an utterance is derived (see Carston I998b) and brief discussion in section 4 of this paper). But this is not B-R's view; his whole enterprise rests on the 
assumption that sentences encode propositions, truth-evaluable entities. Yet, the sentences at issue appear not to be fully propositional AND the default implication induced by the CTB is non-truth-conditional; it seems to follow that utterances of this sort do not actually express a full proposition, so do not have determinate truth-conditional content.

If the semantic representation of a sentence of the form ' $T$ he $F$ is not $G$ ' is not fully propositional, it is not truth-evaluable, so such a sentence is neither true nor false, and we have a truth-value gap. But this, of course, is not the right source of the truth-value gap intuition which presuppositional theories try to capture, since it applies equally to cases where the existential presupposition is true (for example, 'there is a British prime minister'). This is at odds with the logic of the theory, according to which sentences with true presuppositions are either true or false. If the result of the application of the $\mathrm{CTB}$, the affirmation of the existential implication, were able to contribute to the truth-conditional content of these utterances, then they would indeed be either true or false, but so would sentences with false presuppositions (which are supposed to be truth-valueless). Again, there seems to be a tension between the non-semantic account of P-preservation and the logic of a semantic theory of presupposition.

\subsection{Reanalysis in terms of metarepresentation}

Throughout his work on these presupposition-denial examples, B-R poses this question: what triggers the reanalysis into 'metalinguistic negation'? As he says, the answer that is implied by his (1993/7) account and the answer that is given quite explicitly in my (I994) paper (and presented more fully in I998a) are remarkably similar. They both involve the derivation of a contradiction and it is this that triggers the process of reinterpretation; in both cases the contradiction derived is not a function of the encoded semantic content alone but involves a further non-semantic process, a pragmatic one for me and an automatic cognitive one for him.

However, I want to emphasize that the question just posed is but a particular case of a broader question: quite generally, what motivates the move to an interpretation involving metarepresentation? Notice, by the way, that this question, like the more specific one asked by B-R, assumes that, when there is no explicit indicator of a metarepresentational use, the interpretation tried first is inevitably entirely descriptive (that is, it does not involve metarepresentation). This is false, as I have argued in the two papers referred to above: in certain contexts the metarepresentational interpretation is simply the most accessible one. So these questions arise for just those metarepresentational cases where a descriptive interpretation is IN FACT the first one tested for adequacy.

The wider question concerning metarepresentation is probably a subcase of an even wider one: when an analysis is rejected and a pragmatic process 
of reanalysis is undertaken, what motivates that reanalysis? The general answer to all three of these progressively more inclusive questions is: an interpretation is rejected and a reanalysis undertaken when that first interpretation fails to meet whatever pragmatic criterion communicators employ in settling for a particular interpretation as the intended one. There are a variety of criteria on the market involving a variety of notions, including truth/plausibility, informativeness, relevance and coherence. The issue of which of these is correct does not matter here, besides which a contradiction is bound to fail any and all of these criteria: contradictions are false, uninformative, irrelevant and incoherent. The central point, though, is that reanalysis is the result of an interpretive dead-end, diagnosed as such by whatever general principles/criteria constitute one's pragmatic theory. Both contradictions and tautologies are surefire ways of missing the target:

(6) (a) The pretty girl isn't (at all) pretty.

(b) The pretty girl is (indeed) pretty.

(adapted from Noh 1998: ch. 3)

On a descriptive interpretation, neither of these is satisfactory. In relevancetheoretic terms, neither achieves any cognitive effects and it is this that leads to a reanalysis, on which the first occurrence of pretty is taken to be echoically used; that is, to represent some other representation (whether an utterance or a thought), attributed to someone, which predicates prettiness of the girl. The reanalysis meets the expectation of relevance since it achieves effects concerning the speaker's disagreement (in (6a)) or agreement (in (6b)) with the view expressed by the producer of the original representation. Any consideration of this wider issue of the motivation for aborting a line of analysis and trying again is conspicuously missing from B-R's discussions (from I989 to I999), despite his phrase 'PRAGMATIC reanalysis'.

\subsection{Assessment of the analyses}

B-R dismisses both Gricean and relevance-theoretic pragmatic accounts of the two stage presupposition-denial interpretations. He himself has no overall pragmatic theory backing his explanation of the interpretive stages, but calls on two distinct forces at work in arriving at the two interpretations, the P-preserving and the metarepresentational: the Cognitive Tendency to Bivalence and the unacceptability of a contradiction. In fact, it's not clear why a contradiction should lead to a METAREPRESENTATIONAL reanalysis as opposed to some other sort of reanalysis (a pragmatic enrichment or loosening of some of the content, or a decision that the proposition expressed is not communicated but is merely the vehicle for the communication of some implicatures, for instance). A contradiction, not derived solely through linguistic decoding, does play its part in my account as in B-R's; the difference is that in mine it is underpinned by a pragmatic theory, built 
around the central definition of optimal relevance, which accounts for why a contradiction is unacceptable. The very same pragmatic theory accounts for the initial P-preserving interpretation, without having to invoke any other principles to do the work.

A final critical point: by following B-R's focus on the interpretation represented schematically in (3), (or as (I8) and (40) in B-R's paper), it is easy to forget that this is only one of the four possible processing routes for presupposition-denials. In certain contexts, a metarepresentational interpretation will be the first interpretation accessed, and there is the less likely, but possible, wide scope descriptive interpretation (whether derived on a first pass or as a result of reanalysis). Such is the rigidity of B-R's account that the only possibility it allows for is the one given in (3) above; in this respect, the P-preserving interpretation seems still to be more semantic than pragmatic, since it arises automatically as a result of the semantics given for negative sentences with a presupposition in the scope of the negation; the cognitive tendency to bivalence cannot but complete the work started by the encoded semantics (see B-R (I999: 353)). I note also that the point made in Carston (I998a: section 6.2) about clause-reversed presupposition-denials, such as (7a) still stands:

(7) (a) There is no F, (so) the $F$ is not $G$.

(b) The F is not $G$, (as) there is no F.

Although putting the correction clause first will generally preclude the derivation of the contradictory interpretation, which leads to a reanalysis, BR's account predicts exactly the same interpretive stages for (7a) (hence double processing), as are standardly involved in understanding the ordering in (7b), which is the only sort of case he considers. This important problem for B-R's account remains to be addressed.

\section{The Semantics/Pragmatics Distinction again}

$\mathrm{B}-\mathrm{R}$ raises questions about what the semantics/pragmatics distinction amounts to. He points out that there are various ways of construing 'semantics': as encoded linguistic meaning, as the truth-conditional content of the minimal proposition expressed (something like Grice's 'what is said') or the truth-conditional content of some richer, pragmatically augmented, proposition expressed. I agree. However, it doesn't follow from this that my use of the distinction in the paper under discussion is unclear or unhelpful, since it is plainly stated that the distinction involved, the semantics/ pragmatics distinction of Relevance theory, is one between the meaning that is encoded by the linguistic system itself and the further meaning that is communicated. So it entails a distinction between two types of cognitive process employed in understanding utterances: decoding and inference. For quite detailed discussion of the distinction viewed in this way, and of a range 
of other ways of drawing it, on the basis of different ways of construing semantics, see Carston I 998 c.

B-R takes issue with my suggestion that he has a "conception of pragmatics as a fairly thin icing on a substantial semantic cake'. He points out that both of our analyses of presupposition-denials, shown in (3), seem roughly equal in their relative apportionings of interpretive work to semantic decoding and to pragmatics (or, at least to whatever processes are responsible for the derivation of unencoded utterance meaning). Let's suppose that is right, setting aside the issues of just what status to give to the Cognitive Tendency to Bivalence, and the inability of the nonsemantic part of B-R's account to capture the various other possible interpretive routes, as mentioned in the previous section.

However, he and I understand the 'cake/icing' metaphor differently. He takes the cake to be semantics and the icing pragmatics and, in objecting to the quoted statement, emphasizes his taste for thick icing. I prefer to keep the cake large and rich, and the icing thin; it's just that PRAGMATICS IS THE CAKE and semantics is the icing. On the relevance-theoretic conception, pragmatic inferential activity is an automatic response of receivers of ostensive stimuli (which carry a presumption of optimal relevance); it is but a particular instance of our general propensity to interpret human behaviour in terms of the mental states (beliefs, desires, intentions) of the behaver, which, in its turn, is to be located within a bigger picture of general relevance-seeking information processing. According to this view, pragmatic inference is fundamental (the cake) and the employment of a code (linguistic system) as an ostensive stimulus is a helpful addition (icing). This has been argued for in considerable detail by Sperber \& Wilson (1986/95), Sperber (1994) and Carston (I998b), and is backed up by evolutionary considerations in Sperber (I990).

On my account of the interpretation of utterances of negative presuppositional sentences, pragmatic inference mediates between the linguistically encoded content and the P-preserving proposition expressed, which is the truth-conditional content of the utterance. B-R (I999: 356) refers to 'Carston's own suggestion (I998b) that IMPLICATURES may contribute to the explicit truth-conditional content of what is communicated'. This is misleading, since implicatures are, by definition, non-truth-conditional. An important idea in Relevance theory (around at least as far back as Wilson \& Sperber 198I) is that relevance-guided pragmatic inference contributes to the derivation of what is communicated explicitly as well as to what is communicated implicitly (implicatures). In addition to the two obvious processes of disambiguation and reference assignment, there are pragmatic processes of recovering unarticulated constituents, of enriching the lexically encoded content, of loosening the lexically encoded content, and of overriding aspects of linguistic content altogether (in the case of recognized slips of the tongue). The inference to a P-preserving interpretation of 'The F 
is not $G^{\prime}$ is a case of pragmatic enrichment. These various pragmatic inferences do not eventuate in implicatures, but develop the underspecified logical form, linguistically encoded by the utterance, into the proposition the hearer takes the speaker to have communicated explicitly.

\section{Metarepresentation and negation}

In Carston (I 1994, I996), I reanalysed Horn's cases of metalinguistic negation as cases of echoic negation, where an echoic use is one which involves metarepresenting and attributing an utterance (or part of) or a thought (or part of), and expressing an attitude to it (broadly, either endorsement or dissociation). The negation operator is its standard truth-functional self, but some of the material falling within it is used echoically; in the case of an echoed UTTERANCE (as opposed to thought), the focus of the negation could be a matter of form or of content. While broadly supporting this, B-R makes the point that '... since we don't generally issue denials out of the blue, a vanishingly small proportion of attested uses of negation will fail to be relevant examples by her echo criterion' (B-R I999: 362); it follows that, if our intuition about the distinct nature of truly metaliNGUISTIC cases is to be captured, finer classification within this broad category of echoic negation is required. This is an important point, which I shall try to address. In the next section, I look at a range of types of metarepresentational use, before coming to the very specific phenomenon of '! $\mathrm{MN}$ ', whose properties, as B-R has shown, are especially well highlighted by the two possible interpretations of echoed slips of the tongue, discussed in section 5.2. In the final section, I return to the issue of the interpretation of the negation operator itself.

\section{I Types of metarepresentational use ${ }^{3}$}

There are several closely related, but subtly different, terms in play in this general area, including 'metarepresentation', 'mention', and 'echo'. The broadest of these is the first, and while I do not think that all negation is echoic, it may well be that all negation is metarepresentational. Consider the following diagram of types of metarepresentational use, which draws on the much more detailed survey in Wilson (forthcoming):

[3] This section owes a great deal to recent work on metarepresentational use within relevance theory by Eun-Ju Noh and Deirdre Wilson; see references.

[4] I am not drawing here the finer distinction made in Relevance theory between attributive use, whose relevance lies with the information reported and echoic use, which can be thought of as an attributive use whose main relevance lies with the attitude expressed to the attributed representation. Direct and indirection quotation are cases where an utterance or thought is attributed without the speaker necessarily expressing her attitude to the representation. When a representation is used attributively within the scope of negation, a speaker cannot but express a dissociative attitude to the representation. For further discussion (and some disagreement) see Noh (I998: ch. 3). 
NOTES AND DISCUSSION
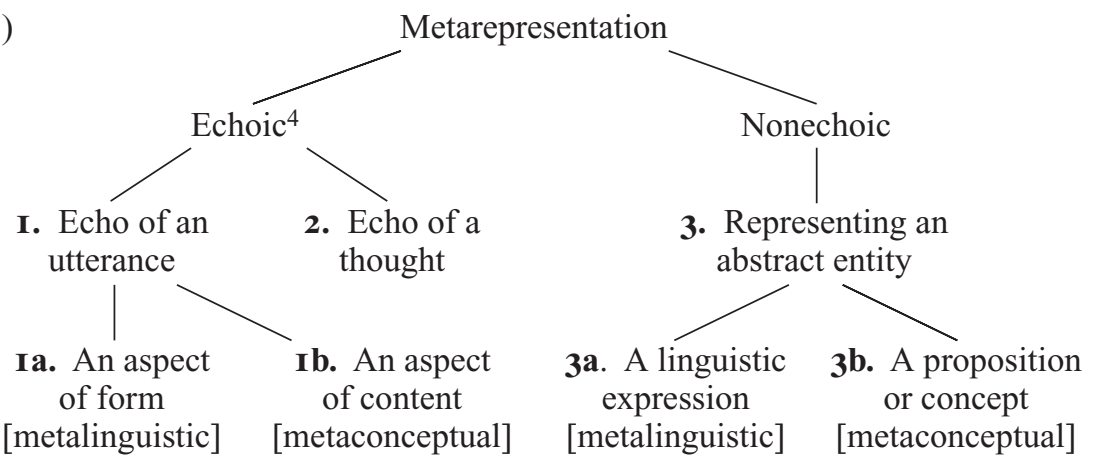

Naturally, all of these types of metarepresentational use can occur in both positive sentences and negative sentences. Here's an example of each type of use, where the fact that it is metarepresentational is not overtly signalled (for instance, by a phrase like $\mathrm{X}$ as you put it, or the word $\mathrm{X}$ ), but has to be pragmatically inferred:

(9) A: I'd like tom[eiDouz] for lunch.

B: I'm not very keen on tom[eiDouz].

(Io) A: It's a lovely day.

B: It's not a lovely day; it's humid and heavy.

(I I) Boston has two syllables.

(I2) John is a bachelor entails John is unmarried.

In (9) and (IO), B echoes an aspect of A's utterance, in (9) her pronunciation of the word tomatoes (a case of (Ia) in the diagram in (8)), in (IO) the proposition she expressed (( $\mathrm{Ib})$ in the diagram). In (9) there is a further pragmatic indeterminacy, in that she may be expressing her dislike of the fruit tomatoes and playfully imitating A's pronunciation, or she may be expressing disapproval of the pronunciation and saying nothing at all about the fruit (unless she follows up with "but I do like tom[a:touz]" or "and I don't like tom[a:touz] either"). If B's utterance in (IO) had not been preceded by A's, it could have been intended as an echo of a thought that she attributes to A (so an instance of (2) in the diagram). Examples (I I) and (I2) involve metarepresentation of the word Boston and the proposition 'John is a bachelor', respectively (so are cases of (3a) and ( $3 b$ ) in the diagram). Note that the only difference between (Ia) and (3a), and ( $\mathrm{Ib}$ ) and (3b), is that in the former, but not in the latter, the metarepresented material is treated as a property of an utterance or thought, either actual or potential, attributed to some particular speaker. As far as I am aware, the term 'mention' has been standardly used for cases that fall under (3) (especially (3a), metalinguistic), such as (I I), where "Boston" is used to refer to the word Boston, not to someone's utterance of the word Boston. 
I need to do two things before attempting to locate B-R's '! $\mathrm{MN}$ ' in this picture. I have to address his point that it begins to look as if all cases of negation are echoic, in which case my reconstrual of Horn's MN as echoic negation seems to lose the intuitively clear distinction between the metalinguistic cases and ordinary descriptive negations. Secondly, B-R characterizes his narrower class of ! MN as involving an "echoic use/mention mix', so I will take a look at different ways in which use (that is, truth-based representation) and metarepresentation (resemblance-based representation) may occur together in one and the same utterance.

The example in ( $\mathrm{IOB})$, in which the content of someone's utterance or thought is echoed, seems, on the face of it, indistinguishable from a case of descriptive negation. However, I think there is a distinction to be made, though it is a subtle one. Wilson (forthcoming) attributes to Dan Sperber the suggestion that, though not all negative utterances are echoic, they may all be metarepresentational. That is, cases of what are thought of as descriptive negation may, in fact, involve non-echoic metarepresentational use; they may metarepresent propositions or abstract hypotheses not attributed to anyone and so fall into category ( $3 \mathrm{~b}$ ) in the diagram. This idea captures the widespread intuition that negative sentences/utterances are marked, relative to their corresponding positives, and that processing of a negative in some sense presupposes the availability of the corresponding positive (see Horn I989: ch. 3). Whether ( $\mathrm{IOB}$ ) is interpreted as descriptive (that is, as the negation of a metarepresented proposition) or as echoic (that is, as a case of expressing dissociation from an attributed thought or utterance) is a matter for pragmatic inference, and may yield differences in cognitive effects.

This goes some way toward meeting B-R's objection that the vast bulk of actual utterances of negative sentences will qualify as echoic 'since we don't generally issue denials out of the blue'. There are denials which are not echoic but which are metarepresentational; that is, they deny the existence of a state of affairs by negating an accessible hypothesis that it does exist. However, as B-R insists, there are finer distinctions to be made, distinctions within the general category of echoic negations, subclasses characterized by what sort of representation is echoed (phonological, lexical, syntactic, conceptual, etc) and, crucially, how this is combined with elements of descriptive use within the same utterance.

Consider some examples of metalinguistic use combined with genuine descriptive statements, cases known as 'mixed quotation' in the literature (see, for instance, Seymour 1994, Cappelen \& Lepore 1997a and Tsohatzidis I998). The examples are adapted from Noh (I998: ch. 2).

(I3) A: Have some tom[eiDouz].

BI : I had some tom[eiDouz] for lunch.

B2: I won't have those tom[eiDouz]. They look rotten.

B3: I won't have those tom[eiDouz], as you call them. 
BI states that he had tomatoes for lunch, and simultaneously echoes an aspect of A's pronunciation, perhaps for some sort of playful effect. Similarly, B2 makes a descriptive statement with her negative utterance, while also echoing the phonetic form 'tom[eiDouz]'; she expresses the proposition that she does not want a particular set of tomatoes, while also echoically metarepresenting an aspect of A's pronunciation. Note also that, as in the standard cases of metalinguistic negation, the echoic use is not explicitly encoded, as it is in $\mathrm{B}_{3}$. But $\mathrm{B}_{2}$ is not a case of ! MN, or even of $\mathrm{MN}$ in Horn's wider sense, as we see when we compare it with a clear example of the phenomenon of interest to B-R:

(I4) She doesn't like tom[eiDouz], but she's quite fond of tom[a:touz].

One of the differences between this sort of case and the cases of mixed quotation is that the ultimate point of (I4) is not to make any descriptive statement concerning tomatoes at all, but to explicate a linguistic or conceptual mistake. In ! MN the echoed element is the focus of the negation, while in (I3) it effectively lies outside the scope of the negation. To further elucidate what he means by a use-mention mix, B-R compares two different interpretations of B's utterance in ( $\mathrm{I} 5$ ), depending on whether it is an answer to $(\mathrm{A} I)$ or a response to $\left(\mathrm{A}_{2}\right)$ :

(I5) Ar: What's the correct pronunciation of this word? Is it eSOTeric? A2: Myra's poem is totally eSOTeric.

B: It's not eSOTeric - it's esoTERic.

Once reference is correctly assigned to the two pronouns, in the two cases, we get:

(I6) (a) The correct pronunciation of this word is not eSOTeric-the correct pronunciation of this word is esoTERic.

(b) Myra's poem is not eSOTeric-Myra's poem is esoTERic.

What are the crucial properties distinguishing (I6a) and (I6b)? A striking one is that (I6b) requires a great deal more pragmatic inference before the hearer will have arrived at the intended final interpretation, while there is no obvious further pragmatic indeterminacy to be resolved in (I6a). Compare each of them with the following approximate but indicative representations of the proposition recovered as part of the final interpretation in each case:

(I7) (a) not (the correct pronunciation of the word esoteric is [eSOTeric]); (the correct pronunciation of the word esoteric is [esoTERic])

(b) not (the correct pronunciation of the word esoteric used to describe Myra's poem is [eSOTeric]; the correct pronunciation of the word esoteric used to describe Myra's poem is [esoTERic]

A comparison of ( $\mathrm{I} 6 \mathrm{~b}$ ) with ( $\mathrm{I} 7 \mathrm{~b}$ ) shows that much of the final interpretation of ( $\mathrm{I} 6 \mathrm{~b})$ is implicit, requiring considerable pragmatic supplementation. 
Furthermore, in many contexts, the most accessible interpretation of the negative sentence, processed first on its own, is very different from that given in ( $\mathrm{I} 7 \mathrm{~b})$. It is an interpretation along the lines of the mixed quotation case in (I3B2): the speaker is taken to be disagreeing with some aspect of the CONTENT of the previous utterance, while also echoing (by the way, as it were) a particular formal property of that utterance: the speaker's stress pattern on the word esoteric. However, the hearer will be forced to reject this interpretation and do another round of processing before the final interpretation is reached; that's the purpose of the second (correction) clause, which is clearly an essential component of !MN. In the standard 'mixed quotation' cases, the descriptive interpretation is the main element of what is communicated, while in the ! MN cases the formal echo (and its correction) is the central point and the descriptive interpretation is an amusing diversion. So, as regards the diagram in (8), ! MN is a subclass of (Ia), the echo of a formal aspect of an utterance, but it is a subclass with rather special additional properties.

As well as (in fact, as a result of) this particular 'tricky, humorous mixture of use and mention', in all instances of the phenomenon of !MN, a contradiction is recovered in the process of interpretation. The relation of contradiction holds between the negative sentence and the follow-up correction clause, so it is clear that cases of ! MN must all have this two-

clause structure. No negative sentence on its own is going to be a case of !MN. B-R says it is a pragmatically derived contradiction, but I assume he means either a semantic or a pragmatic contradiction. The contradiction may be a function of semantic encoding (as in the cases where a formal linguistic property is the focus of the negation and correction, such as (I4) above) or it may be a result of a pragmatic (or, at least non-semantic) inference, which strengthens the negative utterance in such a way that it becomes inconsistent with the following correction clause. A pragmatically induced contradiction arises in the case of the P-denials, as discussed in section 3 above, and, according to $\mathrm{B}-\mathrm{R}$, it also occurs on a certain interpretation of metalinguistic negations involving the correction of slips of the tongue. I look at these, and at the contradictoriness requirement more generally, in the next section.

\section{$5.2^{\prime} ! M N$ ' and the contradiction requirement}

For communication to succeed it is sometimes necessary for pragmatic inference to overrule the determinate dictates of the linguistic system, and this it is often able to do. Consider some examples of this:

(I8) (a) She always flaunts the rules.

(b) The penguins have eaten all our cabbages. (spoken in an English garden)

In (I8a) the speaker uses the wrong lexical form for her intended concept of VIOLATE, either because she simply has the wrong concept-form mapping 
in her lexicon or because she has made an on-the-spot slip of the tongue from flout to flaunt; (I8b) is, most likely, of the latter production error variety. In many instances, these will be correctly interpreted, that is, interpreted in line with the speaker's informative intention, although she hasn't produced the best possible linguistic evidence to ensure fulfilment of that intention. ${ }^{5}$

$\mathrm{B}-\mathrm{R}$ makes the interesting and important point that there are two quite distinct interpretations of B's utterance in (I9), both of which involve recognizing that B is echoing A's mistake.

(i9) A: She always flaunts the rules.

B: She doesn't FLAUNT the rules; she FLOUTS them.

In the one case, B is echoing the concept SHOW OFF, objecting to it and correcting it to VIOLATE; in the process, she is also echoing the linguistic form used, but is not objecting to it per se. In the other, she is echoing and correcting just the lexical form used by the original speaker to express the concept VIOLATE and, although also metarepresenting that concept, which she takes the speaker to have intended, is not objecting to it. In the first case, the echo is metaconceptual, while in the second, we have a purely metalinguistic echoic use. On an entirely descriptive understanding (perhaps accessed before the echoic use is recognized), the propositional content of the two interpretations is as follows:

(20) (a) X doesn't show off the rules; she violates them.

(b) X doesn't violate the rules, she violates them.

So while both of the ultimate intended interpretations are cases of echoic negation, as I have defined it, only the second one, which involves the descriptive contradiction in (2ob), and an echo and correction of a formal linguistic property, is a case of the phenomenon of $! \mathrm{MN} .{ }^{6} \mathrm{~A}$ more transparent representation of B's utterance on this interpretation would be (2I), where the bracketings enclose phonetic representations:

(2 I) She doesn't [flo:nt] the rules; she [flaots] them.

Whether these examples are cases of pragmatic contradiction, as B-R maintains, or of semantically (mis)encoded contradiction is not perfectly

[5] The importance of these misuse examples as data for a cognitively-based pragmatics, such as that of Relevance theory, is discussed briefly in Carston (I998b, I998c), and in more detail in Carston (in preparation).

[6] Something like the converse of this phenomenon may also occur:

(i) I didn't buy any tom[eiDouz] but I did buy some tom[a:touz].

(ii) It isn't mongeese that have caused the damage; it's mongooses.

Here the idea is that mongeese and mongooses are to be taken as encoding distinct animal concepts and so as having different extensions; this is either intended as a jokey pretence (a suggestion made by McCawley (I99 I : 190)) or the speaker in fact believes, mistakenly, that they encode distinct concepts (see B-R's (I999) example (32), where El Kuds and Jerusalem might be believed by the speaker to name different cities). An account of the processes involved in the different possible understandings of these examples remains to be given. 
clear to me. The pragmatic work of recognizing that flaunt is taken to encode VIOLATE in the exchange in (I9) is undertaken by B in her understanding of A's initial utterance; since it is A's (mis)encoding, when their roles switch and $\mathrm{A}$ is the interpreter of $\mathrm{B}$ 's response, $\mathrm{A}$ derives the descriptive contradiction in (2ob) by decoding alone. I don't think the example is essentially different from the 'tom[eiDouz]/tom[a:touz]' and 'mongeese/ mongooses' cases. (There is a large issue looming here around whether a language is to be conceived of as fundamentally idiolectal or social/ communal.)

Of the instances of ! MN that B-R discusses, only the presuppositiondenials are clearly pragmatic (or, at least, non-semantic). A corollary of this is that presupposition-denials are also alone in that what is being objected to is not some aspect of linguistic form but is a matter of content; given a metalinguistic/metaconceptual distinction as in the diagram in (8), these are cases where the echoic use is metaconceptual, though they have the key properties of ! MN : tricky use/mention mix, descriptive contradiction and an echoic reanalysis. Question: are there any other metaconceptual cases of !MN and should !MN be understood as crosscutting the metalinguistic/ metaconceptual distinction?

Consider the following examples:

(22) (a) A: You're not going to sack him, are you?

B: No, I'm not going to sack him; I'm going to kill him.

(b) A: That letter has to reach Bill by tomorrow at the latest. I hope you've put it in the mail.

B: I haven't put it in the mail; I've delivered it to him by hand.

(c) No, young man, smoking marijuana isn't a misdemeanour in these parts; it's a felony.

(d) Keeping the kids entertained isn't cheap; it's free, when you visit our megastore.

(e) We don't sell cheap cars; we sell cars cheap.

These are mostly attested cases (variously from TV shows and motorway billboards); they all have the standard format of a negative sentence followed by a correction clause and achieved, for me at least, the sort of rhetorical effects (due to descriptive garden-pathing and consequent reanalysis) typical of cases of !MN. They are clearly not descriptive contradictions as a matter of linguistic encoding: killing someone doesn't entail sacking him, delivering a letter by hand does not entail mailing it, being a felony doesn't entail being a misdemeanour, etc. Are they pragmatically derived contradictions? It does seem that on a first processing pass, the overall interpretation of the negative sentence (that is, the proposition expressed and implicatures) is inconsistent with the proposition expressed by the following clause. For instance, in (22a), the negative clause may be interpreted along the lines of 'I will do something less bad than sack him (perhaps, just reprimand him)'; in (22b), 'The letter 
won't reach Bill by the required time'; in (22c), 'The marijuana smoker won't be charged with a criminal offence'; in (22d), 'Keeping the kids entertained is an expensive business'; in (22e) 'Our cars are expensive'. So, on a wider, pragmatic, conception of contradiction, it would seem that these cases do meet the contradiction requirement of ! MN. There is a 'use-mention mix' too, though what is mentioned (or, in my terms, echoed) is conceptual rather than linguistic/formal; as a result of the metaconceptual reanalysis, the proposition recovered is something like the following:

(23) not (the correct description of what I'm going to do to is 'sack him'); (the correct description of what I'm going to do is 'kill him').

I offer a last set of examples for consideration:

(24) (a) I didn't buy a car; I bought a dream. [uttered by a man shortly after buying James Bond's car]

(b) Bill isn't a butcher; he's an artist. [where Bill is, by profession, a butcher]

(c) John's not a man; he's a machine.

Again, these are not descriptive contradictions by virtue of semantic encoding: being a dream doesn't entail being a car, being an artist doesn't entail being a butcher, etc. Does first pass processing result in a pragmatic contradiction, as B-R requires of cases of ! MN? In processing (24a), which occurred in a radio interview, I was briefly baffled by my initial descriptive interpretation of the negative utterance, since it was blatantly contradicted by the highly salient contextual assumption that he had indeed bought a car (which was the subject of the interview). The metaphorical use in the followup clause, and the processing that that involved, prompted a reanalysis of the negative sentence, perhaps along the following lines:

(25) not (what I bought is appropriately termed 'a car')

These examples do have many of the processing properties of B-R's cases of !MN, but I remain unsure whether they qualify or not. ${ }^{7}$

Finally on this contradiction issue, let's return to the presuppositiondenials. Recall that a major motivation for $\mathrm{B}-\mathrm{R}$ in distinguishing the phenomenon of ! MN was to establish it, rather than broader notions of metalinguistic or echoic negation, as giving rise to the relevant complex of cognitive and pragmatic processes involved in accounting for presuppositioncancellation, which is semantically impossible in his theory. The explanation

[7] An alternative analysis of some examples of this sort is advanced in Carston (1997), according to which the reprocessing results, not in anything metarepresentational, but in an ad hoc concept in the scope of the negation, constructed by a pragmatic process of narrowing an encoded lexical concept. For instance, the CAR concept is narrowed to one which excludes certain atypical cars, such as that of James Bond; the BUTCHER concept is narrowed so as to denote just your average prototypical butcher, etc. 
in terms of ! MN should, therefore, account for the interpretation of both of the following, since both are cases of a presupposition-cancelling interpretation:

(26) (a) The king of France isn't handsome, since there is no king of France.

(b) There is no king of France, so the king of France is not handsome.

As discussed briefly in section 3.4 above, intuitively, there is a difference in the inferential processes required in the interpretation of each of these; although (26b) probably involves an echoic use of the phrase the king of France as in (26a), it does not (or is much less likely to) involve descriptive garden-pathing, resulting in a contradiction, and consequent pragmatic reanalysis. The explanation for this is that the correction clause (denying the existence of the king of France) is processed first, and so blocks a descriptive interpretation of the following definite description. Then (26b) is not obviously a case of ! MN, because a descriptive contradiction is not derived in its on-line processing. It seems that $! \mathrm{MN}$ is too narrow and particular a phenomenon to serve in the general pragmatic account of presuppositioncancellation cases, which B-R's semantic account of presupposition needs, and that, after all, my wider notion of echoic negation is the appropriate one here.

\subsection{Truth-functional negation and the rhetorical device of '!MN'}

Paraphrasing B-R, ! MN is that subset of cases of implicitly echoic negation which have the following properties:

A. They involve two stages of processing; first, a tier of descriptive interpretation, which is rejected, and second, an echoic interpretation.

B. The rejection is caused by a contradiction derived in the on-line, left-toright pragmatic processing of the utterance as descriptive.

C. The negation operator on the final metarepresentational interpretation is understood non-truth-functionally.

I turn now to the third of these characteristics. Discussing the 'Myra's poem' example (( $\mathrm{I} 6 \mathrm{~b})$ above), B-R says: '! MN is non-truth-functional in this sense: it involves a departure from the interpretation implied by construing the negation as operating on the truth value assigned to the USE of a predicate descriptively applied to the referent of the subject (Myra's poem). Instead it conveys an objection to something (a pronunciation) not subjectable to a truth function like negation' (B-R I999: 360). Horn (I989: 434) makes a very similar point in response to my earlier assertion that, in all cases of metalinguistic negation, the negation operator is truth-functional. I won't repeat in full the arguments given in Carston \& Noh (I995: 6-IO) and Carston (1996: 327-29), which, as far as I am aware, have not been countered, or even addressed. Still, it's worth recalling in this context the 
Gershwin song Let's call the whole thing off, which begins 'You like po-tayto and I like po-tah-to'. Does this case of a 'tricky use-mention mix' render the conjunction operator non-truth-functional? Surely not.

Noh (1998: ch. 3) adds further support for our truth-functional view, by presenting a range of examples which have all the crucial properties of ! MN, but which cannot possibly be held to involve some special meaning in the negation operator, since there is no negation operator:

(27) (a) A: Would you like some tom[eiDouz]?

B: Well, I'd prefer some tom[a:touz].

(b) A: Did you see mongeese?

B: I only saw mongooses.

On an initial descriptive interpretation, B's utterance in (27a) is contradictory, as shown in (28a); on an echoic reanalysis, the proposition recovered is along the lines of $(28 b)$.

(28) (a) B prefers tomatoes to tomatoes.

(b) B prefers to have something described as 'tom[a:touz]' rather than something described as 'tom[eiDouz]'.

Here we effectively have ! MN without negation; presumably, the verb prefer is not to be given an interpretation that differs from its standard descriptive one.

What Noh and I want to emphasize is that, while there is no reason to suppose that the negation operator takes on a non-truth-functional meaning, there is certainly much pragmatic work required in recovering the propositional form which falls within the scope of this truth-functional negation, in the final interpretation of the utterance. This has already been indicated above in examples ( $\mathrm{I} 7 \mathrm{~b}$ ) and (23). Let's review the representational stages involved in interpreting example (I6b).

(29) (a) not (Myra's poem is esoteric); Myra's poem is esoteric.

(b) not (Myra's poem is 'eSOTeric']; Myra's poem is 'esoTERic'.

(c) not (Myra's poem is correctly described using the pronunciation 'eSOTeric']; her dissertation is correctly described using the pronunciation 'esoTERic'.

(29a) is the proposition taken to have been expressed on the initial descriptive interpretation; it has been developed from the encoded logical form; since it is contradictory, it is rejected. As B-R says, the only perceptible (or, at least, the most perceptible) difference between the two sentences uttered (apart from the polarity difference) is the pronunciation of the word esoteric, so it seems that attention is being called to that, rather than to any aspect of content. Since pronunciation is not a matter of conceptual content, but, in the normal course of things, a vehicle for making public some conceptual content, it has to be treated here as a case of mention or metarepresentation, 


\section{JOURNAL OF LINGUISTICS}

as in (29b). This representation is not propositional, that is, it is truthconditionally underspecified; it does not encode a coherent, truth-evaluable form. However, it does not follow from this that the 'not' receives a nontruth-functional interpretation. Under pressure to find the relevant propositional form, the pragmatic mechanism responds to the clues it has (the descriptive interpretation of esoteric having been ruled out) and enriches the form in (29b) to that in (29c) which, as B-R says, is 'the only coherent, rational overall interpretation'.

Finally, what sort of a phenomenon is ! MN? Why should this particular small subclass of cases of echoic negations, with this odd admixture of properties, be singled out? The answer seems to lie not with any particular linguistic or pragmatic status it has, but with its rhetorical effectiveness. The inferential processing it triggers results first in a garden-path, followed by easy rerouting along a new line of interpretation; the effects are both humorous and corrective. It is a rather curious fact, perhaps worth some reflection, that a great deal of heavy-weight theoretical reshuffling, in accounting for the interaction of negation and presupposition, has been prompted by a verbal scheme whose main feature is its comic potential. ${ }^{8}$

\section{REFERENCES}

Breheny, R. (1999). Context-dependence and procedural meaning: the semantics of definites. $\mathrm{Ph} . \mathrm{D}$. dissertation, University of London.

Burton-Roberts, N. (1989a). On Horn's dilemma: presupposition and negation. Journal of Linguistics 25. 95-I25.

Burton-Roberts, N. (1989b). The limits to debate. Cambridge: Cambridge University Press.

Burton-Roberts, N. (1993). On preservation under negation. Newcastle and Durham Working Papers in Linguistics I. I 8-4I. [Reprinted (1997) in Lingua IoI. 65-88.]

Burton-Roberts, N. (1999). Presupposition-cancellation and metalinguistic negation: a reply to Carston. Journal of Linguistics 35. 349-364.

Cappelen, H. \& Lepore, E. (I997a). Varieties of quotation. Mind I06. 429-450.

Cappelen, H. \& Lepore, E. (1997b). On an alleged connection between indirect speech and the theory of meaning. Mind and Language I2. 278-296.

Carston, R. (I994). Metalinguistic negation and echoic use. UCL Working Papers in Linguistics 6. $32 \mathrm{I}-339$.

Carston, R. (I996). Metalinguistic negation and echoic use. Journal of Pragmatics 25. 309-330. [Revised and expanded version of Carston (1994).]

Carston, R. (1997). Enrichment and loosening: complementary processes in deriving the proposition expressed? Linguistische Berichte 8: Special Issue on Pragmatics. I03-I27.

Carston, R. (I998a). Negation, 'presupposition' and the semantics-pragmatics distinction. Journal of Linguistics 34. 309-350.

Carston, R. (1998b). Pragmatics and the explicit-implicit distinction. Ph.D. dissertation, University of London.

[8] My focus has been on some of the pragmatic issues raised by types of metarepresentational use. It should be noted that there is also much current work on metarepresentation (usually viewed as 'quotation' of some sort or other) within the truth-conditional semantics framework; see, for instance, Seymour (1994), Cappelen \& Lepore (I997a, I997b), Saka (I998), Tsohadzidis (I998). 


\section{NOTES AND DISCUSSION}

Carston, R. (I998c). The semantics/pragmatics distinction: a view from relevance theory. UCL Working Papers in Linguistics I0. 303-329. [Longer version to appear in K. Turner (ed.), The semantics/pragmatics interface from different points of view (CRiSPI I). Elsevier Science.]

Carston, R. (in preparation). What did Mrs Malaprop say?

Carston, R. \& Noh, E-J. (I995). Metalinguistic negation is truth-functional negation, with evidence from Korean. UCL Working Papers in Linguistics 7. I-26. [Reprinted (1996) in Language Sciences I8. 485-504.]

Green, M. (I995). Quantity, volubility, and some varieties of discourse. Linguistics and Philosophy I8. 83-I I2.

Grice, H. P. (I98I). Presupposition and conversational implicature. In Cole, P. (ed.), Radical pragmatics. New York: Academic Press. I83-198. [Reprinted in Grice, H. P. (1989). Studies in the way of words. Cambridge, MA: Harvard University Press. 269-283.

Horn, L. (1985). Metalinguistic negation and pragmatic ambiguity. Language 6I. I2 I-I74.

Horn, L. (I989). A natural history of negation. Chicago, IL: The University of Chicago Press.

Horn, L. (1990). Showdown at truth-value gap: Burton-Roberts on presupposition. Review of Burton-Roberts i 989. Journal of Linguistics 26. 483-503. Lycan, W. (1984). Logical form in natural language. Cambridge, MA.: MIT Press.

McCawley, J. (I99I). Contrastive negation and metalinguistic negation. Chicago Linguistic Society 27: The Parasession on Negation. I89-206.

Noh, E-J. (1998). The semantics and pragmatics of metarepresentations in English: a relevancetheoretic approach. Ph.D. dissertation, University of London.

Saka, P. (1998). Quotation and the use-mention distinction. Mind I07. I I3-I35.

Seymour, M. (1994). Indirect discourse and quotation. Philosophical Studies 74. I-38.

Sperber, D. (I990). The evolution of the language faculty: a paradox and its solution. Behavioral and Brain Sciences I3. 756-758.

Sperber, D. ( I994). Understanding verbal understanding. In Khalfa, J. (ed.), What is intelligence? Cambridge: Cambridge University Press. I79-198.

Sperber, D. \& Wilson, D. (I986). Relevance: communication and cognition. Oxford: Blackwell \& Cambridge, MA: Harvard University Press. [Second edition I995.]

Tsohatzidis, S. (I998). The hybrid theory of mixed quotation. Mind I07. 66I-664.

Wilson, D. (forthcoming). Metarepresentation in linguistic communication. To appear in D. Sperber (ed.), Proceedings of the Vancouver conference on metarepresentation.

Wilson, D. \& Sperber, D. (I98I). On Grice's theory of conversation. In Werth, P. (ed.), Conversation and discourse. London: Croom Helm. I55-I78.

Author's address: Department of Phonetics and Linguistics,

University College London,

Gower Street

London WCIE 6BT

U.K.

E-mail:robyn@ling.ucl.ac.uk 